\title{
Empresarios, memorias y guerras. Testimonios desde el Pacifico colombiano
}

Luis Fernando Barón y María Emma Wills, editores

Cali: Icesi

2018, 216 páginas

\section{FREDDY A. GUERRERO*}

Pontificia Universidad Javeriana de Cali, Colombia

DOl: $10.22380 / 2539472 X .1053$

llibro Empresarios, memorias y guerras es el resultado de un ejercicio investigativo enmarcado en los procesos de construcción de memorias regionales del Pacífico colombiano. Este esfuerzo, desarrollado por investigadores de la Universidad Icesi, se suma a los del Centro Nacional de Memoria Histórica ( $\mathrm{CNMH}$ ), cuyo trabajo de reconstrucción de memoria histórica ha dejado una producción importante de diez años, con decenas de informes sobre temas asociados a masacres, desplazamiento, desapariciones, violencia sexual, además de enfoques diferenciales en términos de género, minorías étnicas, afrodescendientes, entre otros.

Aun así, como lo señalan María Emma Wills, asesora del CNMH hasta el 2018, y Luis Fernando Barón, coordinador de la investigación, el tema de los emprendedores y empresarios es escaso en la producción asociada a la memoria histórica. Este texto es novedoso en tanto recoge voces de una población que también ha sido receptora de daños originados por el conflicto pero que, por diversas razones, como se explicará más adelante, no es muy visible en las narrativas públicas de la guerra.

La investigación acerca de emprendedores y empresarios del Pacífico se sustenta en un estudio etnográfico fundamentado en la observación participante,

Antropólogo y magíster en estudios políticos, docente y miembro del grupo de investigación Bitacus de la Pontificia Universidad Javeriana de Cali, línea de investigación Memorias, Cultura y Convivencia. faguerrero@javerianacali.edu.co / https://orcid.org/0000-0003-2626-4576 
talleres, grupos focales y revisión de informes académicos e institucionales. A partir de sus testimonios y los de quienes los rodean, recoge experiencias particulares y diversas sobre las maneras de enfrentar el conflicto, para comprender aspectos transversales asociados a la normalización y naturalización de situaciones derivadas de la guerra, las formas narrativas que adquiere el pasado en este sector victimizado, así como sus creencias y las estrategias utilizadas para mantenerse en el territorio con sus emprendimientos y empresas.

El libro aborda la memoria como una esfera simbólica de lo social y, de forma especial, desde los sistemas de representación que se reflejan en ella. Parte de la necesidad de incorporar la memoria en el plano de las relaciones sociales y de considerarla una convergencia de significados y sentidos derivados de las interacciones sociales en lugares específicos. Esta aproximación a la memoria la ubica en contextos que - como el del conflicto y el de otras violencias regionales- resaltan su inserción en un campo de disputas donde entran en juego las disposiciones culturales y los poderes políticos y sociales.

La reflexión teórica y metodológica que se propone desde las disquisiciones sobre la memoria y la narración de Paul Ricoeur es relevante en la configuración de las tramas que, mediante las crónicas y la metáfora del viaje, los autores construyen en un todo coherente y con sentido, como resultado de un proceso de organización espacial y temporal de relatos diversos y singulares. El escenario de fondo es el Pacífico colombiano, lugar de una pluralidad de experiencias que en sus singularidades presentan poblaciones y culturas con hitos históricos y acontecimientos regionales. El viaje se organiza por ríos, esteros y mar, pero también por relaciones comunitarias, familiares y con los actores del conflicto, que permiten comprender las transformaciones y adaptaciones de los emprendedores y empresarios en una región compleja y en permanente cambio.

La complejidad y pluralidad de las experiencias y representaciones de la memoria se infieren del título del libro, por cuanto los sujetos parecieran no ajustarse a las características de otras víctimas del conflicto y la violencia del país. Desde el inicio los autores señalan que los emprendedores y empresarios no son un grupo homogéneo, ni son necesariamente asimilables a las élites. Sin embargo, sí existen algunas características especiales que los distinguen: 1) ver oportunidades y potencialidades para desarrollar actividades en campos económicos y en momentos, lugares o productos donde otros no las ven; 2) tomar decisiones y riesgos en diferentes contextos y con informaciones y capitales diversos; 3) dinamizar campos económicos; y 4) generar recursos y capitales en escenarios cambiantes, inciertos y desafiantes (30-31). No obstante, hay diferencias entre unos y otros. De acuerdo con Varela y Bedoya (2006), entre los emprendedores 
existe una capacidad de anticiparse a los acontecimientos y tienen un conocimiento amplio de sus ámbitos productivos y del entorno, mientras que los empresarios desarrollan nuevas empresas, valores, riquezas y empleos, contando para ello con el análisis de las redes a su disposición (31).

A esta caracterización se suman las narrativas de los emprendedores y empresarios - que, según los autores, son posibles en condiciones épicas y mesiánicas - en las que les dan contenido y sentido a sus experiencias y donde se refieren a sí mismos como víctimas de manera marginal sin autocompasión. Entre esta población, ser receptor del daño pareciera no tener cabida en la noción dicotómica víctimas-victimarios, al ser generalmente representados como parte de sectores o gremios en connivencia con los victimarios, o bien porque tales representaciones sociales identifican a la víctima como pasiva y no acorde con las narrativas épicas de los emprendedores y empresarios. En este caso se entienden las prevenciones expuestas en la introducción del texto, que señalan que esta construcción discursiva y binaria en los procesos de justicia transicional ha prolongado en muchas ocasiones divisiones sociales sustentadas en categorías como las de culpables o inocentes: "investigar y escribir sobre estas memorias, de inmediato, despierta suspicacias, desconfianzas y dilemas que han implicado grandes desafíos y debates éticos, académicos y políticos, dentro y fuera de nuestro equipo de investigación” (22).

La anterior reflexión de Luis Fernando Barón —editor y coautor-señala también la complejidad de las memorias de quienes entregan sus relatos, de las memorias generadas en el convulsionado y resistente Pacífico colombiano y de la recepción pública que genera una investigación de este estilo.

Como lo anota en el prólogo María Emma Wills, el texto es una ventana a la complejidad del conflicto armado. Una de tantas, como las que reflejan las ilustraciones de la carátula y las que preceden cada capítulo, que resaltan precisamente los grises inciertos pero cotidianos del Pacífico; esos matices que demandan reflexividad y una percepción diferente.

La imagen de la carátula presenta una ambigüedad significativa: una lancha que navega en los límites entre el mar y la costa. En una primera percepción la costa aparece agrietada, pero son las líneas del Pacífico, bañado por las vertientes de sus múltiples ríos. Sin duda, estos motivos artísticos expresan la labor de los pobladores en ese entorno y los medios con los que la realizan. Sin embargo, según el punto de vista en que se ubique el lector-observador, la lancha también aparece como un proyectil que irrumpe en un mar blanquecino, como una metáfora de la violencia y la economía ilegal que cuartea y fragmenta el Pacífico representado al fondo. Las imágenes que ilustran el texto intentan superar 
las dicotomías señaladas y las narrativas reduccionistas sobre la violencia y el conflicto: los grises del paisaje y las narraciones que los acompañan presentan una realidad más compleja. De acuerdo con Wills, estas memorias, reducidas en ocasiones al silencio, son parte de un mosaico anclado en experiencias heterogéneas que no se han indagado. El texto es una oportunidad para embarcarse en el viaje por el territorio al que nos conducen las diferentes crónicas.

El libro contiene un prólogo, una introducción que le da la base teórica y metodológica al trabajo del grupo de investigación y cinco capítulos escritos a manera de crónica. Están a cargo de diferentes investigadores que comparten los mismos referentes teóricos y metodológicos, que dan un orden y sentido de conjunto a las experiencias de los emprendedores y empresarios en el territorio.

A la primera crónica se antepone la imagen de trabajadores en actividades de recolección en plantaciones de palma aceitera; en la ilustración que le sigue, otras palmas custodian las tupidas matas de coca que dejan ver un horizonte montañoso y un cielo oscurecido. Este capítulo, escrito por Mónica Castillo, antropóloga y una de las coordinadoras del grupo de investigación, se llama "Sembrando esperanza: entre palmas aceiteras y matas de coca”. En él, el lector viaja a través de las experiencias, tensiones y decisiones familiares, comunitarias y empresariales de Julio Sevillano, don Domitilio, don Homero, Julieta y sus hijos, en un contexto de competencia social, cultural y económica entre los cultivos de palma y de coca. El escenario es Tumaco, o por lo menos es un eje de referencia, pues las trayectorias de los personajes se conectan con otras geografías en situaciones diversas y peregrinas, a partir de la rememoración de los múltiples ensayos y caídas de quienes han transitado por negocios extractivos de materia prima como recursos marinos (carduna), pasando por la explotación de madera, la tagua, la silvicultura y, por supuesto, la palma.

Este capítulo es un buen punto de partida para describir las experiencias de los emprendedores y empresarios del texto en su conjunto, porque no reduce sus vidas a aspectos de orden económico o a la racionalidad limitada a la creación de ganancia, valores, empresas y emprendimientos. Las experiencias también giran en torno a la familia, los amigos, las preocupaciones de la cotidianidad y las dificultades que enfrentan en un territorio de difícil consolidación de iniciativas económicas como las suyas. De forma paralela, aparece una crítica de los emprendedores y empresarios a las condiciones de marginamiento de la región y a la ausencia del Estado, poniendo a contrapelo de esas circunstancias sus propuestas económicas y otras iniciativas propias que aportan en lo local.

La presencia de actores armados y del narcotráfico en el Pacífico desde los años noventa constituye un punto de quiebre por el impacto y las transformaciones sufridas en sus habitantes y en la economía regional. Esta situación 
es el resultado de procesos vinculados a fenómenos en otras regiones del país, como Caquetá y Putumayo, donde la implementación del Plan Colombia, más que eliminar las economías ilícitas, las desplazó al Pacífico. El asesinato por parte de las Fuerzas Armadas Revolucionarias de Colombia (FARC) de don Homero, uno de los protagonistas de la crónica, muestra la tragedia familiar y las formas de enfrentar estas circunstancias adversas. Tal situación hace preguntarse a los autores por qué estos empresarios no se reconocen como víctimas o por qué les genera extrañeza ese reconocimiento.

La crónica describe las estrategias de afrontamiento en espacios donde las opciones de vida y productivas son limitadas, pero donde la competencia con la economía ilegal articulada al conflicto no coarta a los empresarios agrícolas para seguir sembrando esperanza, una metáfora concebida desde su persistencia en sostener los cultivos lícitos por los que han apostado.

La segunda crónica comienza con ilustraciones de embarcaciones ubicadas en las costas y en un embarcadero, que sugieren las labores asociadas a la pesca y al cabotaje. El texto, trabajado por Luis Fernando Barón, se titula "Redes de ríos, violencias y movilización social. Recuerdos sobre las violencias y la paz de empresarios del cabotaje”, y nos conduce por las vidas de don Gratiniano, Javier y Robinson Torres, entre otros, en su mayoría afrodescendientes y con memorias asociadas al mar, los ríos y los esteros. Son historias de generaciones que ven transformado el Pacífico por la creciente población foránea — no toda en la legalidad-y por las irrupciones de grupos armados y el narcotráfico que modifican las formas de vida, entre ellas, las prácticas de pescadores y caboteros. El escenario central es Buenaventura pero hay otros nodos como El Charco, Timbiquí, Satinga, Mosquera, Pital y San Juan, que las labores de pesca y cabotaje unen a esa inmensa red.

En Buenaventura sobresale la participación de Javier, líder de la Asociación de Transportadores Marítimos y Fluviales del Pacífico (Atransmaflupa), desde donde ejerció un liderazgo importante en el comité del paro cívico de Buenaventura del 2017 que inmovilizó el puerto por varias semanas. Con su historia se revelan acciones colectivas importantes que relacionan las demandas contra la corrupción local y por mayor inversión y creación de un fondo particular para programas y proyectos, además de mecanismos de participación e interlocución directa con el Gobierno para un puerto que ha visto transitar riquezas, pero donde solo parecen arraigarse la marginalidad, la pobreza y el desempleo rampante. Para los miembros de la asociación, la memoria se convierte en un aporte a un colectivo más amplio que el del gremio y que se suma a las demandas por hacer 
públicos los sufrimientos, los logros y las memorias a escala local y regional, como señala Javier en la crónica.

La tercera crónica, "Sueño con un Tumaco tranquilo”, escrita por Oscar Ortega, está precedida por imágenes de varios adolescentes jugando con un balón de fútbol en una cancha a la que denominan Las Tesas. La cancha es un apoyo de don Alirio Martínez y su esposa, Lucero Ordóñez —empresarios de lácteos—, a la escuela de fútbol Calimío. Don Alirio, sujeto a extorsiones, ataques y atentados, incluso con pérdidas de personas cercanas, ha adaptado sus prácticas económicas al contexto tumaqueño, negociando su existencia según el orden local que corresponda y aportando a la comunidad en la medida de sus posibilidades. Una de sus apuestas es la escuela de fútbol y la inédita asociación con desmovilizados de las FARC para desarrollar un campeonato de este deporte. Estos encaramientos son parte de procesos de convivencia y reconciliación que promueven algunos de los emprendedores consultados, a pesar de las tensiones en la región por la presencia de los jinetes del narcotráfico, los actores armados y la corrupción.

"'Yo era una bomba'. Memorias de un exmilitar y empresario del Valle del Cauca sobre el conflicto y la paz", de Érika Paredes y Luis Fernando Barón, es el siguiente relato que nos embarca en la experiencia de Octavio, cuyas memorias son ambivalentes frente al deseo de recordar y de reservarse algunos acontecimientos para sí. Su historia está marcada por los estertores del periodo de La Violencia y el drama de las persecuciones y los ocultamientos, y por ser testigo de los horrores de la época - “madurando biche”, como señala Octavio—. Su posterior desplazamiento a la zona urbana lo lleva a desarrollar habilidades en el mundo del comercio y comenzar nuevas experiencias. Haber estado en el ejército lo expone también a las condiciones tempranas de la guerra más reciente de Colombia y el trabajo de inteligencia, y específicamente en el área de operaciones psicológicas, así como sus actividades en áreas logísticas y manejos administrativos, que le servirán por fuera del mundo castrense.

Muchos ensayos de emprendimientos con réditos se presentan en esta crónica, que abre con una cita de Octavio donde reconoce las bondades de un acuerdo de paz y la necesidad de que incluso los miembros de la fuerza pública participen en la reintegración a la vida civil, pues considera que

[...] no solo los guerrilleros requieren pasar por un proceso serio de reintegración. También los soldados: nosotros, los militares lo necesitamos, porque el Estado es tan injusto que ni siquiera es capaz de reinsertarlo a uno a una sociedad que uno no reconoce, después de vivir durante 20 años con un arma en la mano y con el enemigo al frente, usted, en sí, está entrenado para matar [...] (173) 
Resultan interesantes las posibilidades que plantea Octavio al ver un acuerdo de paz como una mejor alternativa que la guerra, pero también reconocer - como exmilitar - que las experiencias de guerra requieren la reintegración no solo de un sector armado sino de la fuerza pública. Esto es importante considerando las formas en que la guerra ha continuado con actores cuyas competencias bélicas son utilizadas para mutar en nuevos conflictos, como se observa con exmiembros de la fuerza pública o grupos paramilitares y guerrilleros que reinciden o se incorporan a otros grupos armados ilegales.

La última crónica, "Blanca la marea, roja la zona, turbia la adversidad”, escrita en primera persona por Marcelo Franco, narra la historia de Luis Hernando Rosas, técnico, financiero, vendedor, cobrador, vigilante, un "todero", según sintetiza el relato. Desde Ricaurte, pasando por Guapi y Tumaco, Rosas se consagra como empresario de una camaronera luego de haber escalado casi todos los roles asociados al área pesquera, donde no le fueron ajenas la extorsión y las propuestas de la economía cocalera. Aunque para Luis Hernando persisten las adversidades, su vocación empresarial le permite dar sentido a su proyecto de vida en espacios que parecieran poco convenientes y riesgosos para desarrollar prácticas productivas.

Un aspecto destacable del libro es que nos presenta las realidades económicas, familiares, comunitarias, sociales y políticas de un sector señalado como cómplice o determinador de las violencias que, sin embargo, no responde como un cuerpo homogéneo a las condiciones de violencia y conflicto con las que interactúan. Los autores aluden de forma particular a Ricoeur (2004), desde la idea de que los textos logran mediar en la comunicabilidad, la referencialidad y la comprensión de la identidad de estos emprendedores y empresarios del Pacífico.

Es importante destacar que los relatos épicos y heroicos de los protagonistas, que le dan a la narración un estilo particular, sitúan en el centro las formas de resistencia y las estrategias para mantenerse a pesar de las dificultades. Así, su identidad como emprendedores y empresarios, aunada a los atributos especiales que se les asignan, en cierto sentido imposibilita su autorreconocimiento como víctimas. Este es un punto de discusión que, por supuesto, implicará pensar en las formas de reconocimiento a las víctimas, los contextos sociales de esta categoría, y las identidades estratégicas que entran en juego en esta figura jurídica e identitaria que se moviliza en Colombia.

Ahora bien, es claro que la investigación y las crónicas no son un ejercicio de denuncia, aunque se reclamen y critiquen las formas de presencia y ausencia del Estado, ni son unas memorias que apelen a la configuración de una identidad para asociar a sus protagonistas como víctimas, en el sentido 
restringido y jurídico del término o bien en sus acepciones de orden social. Tampoco se revela una intención de que estas formas de recuerdo reclamen una justicia que conduzca a la reparación.

No obstante, sí es posible señalar la necesidad de hacer visibles las responsabilidades gremiales y del sector empresarial, de participación indirecta o directa en las acciones desarrolladas por los actores armados en los territorios y por las transacciones que, aunque determinadas por el contexto, se movieron en la ilegalidad y que aún no han sido esclarecidas en el Pacífico. Verdades y responsabilidades que demandan ser visibilizadas, como lo señala el diálogo sostenido en la ciudad de Cali entre los investigadores y la Red Colombiana de Lugares de la Memoria en el 2017, que generó algunas reflexiones precisamente sobre la razón de ser de la investigación reseñada. En este sentido, se trata de investigar las formas heterogéneas mediante las cuales emprendedores y empresarios se articularon en determinados contextos a las violencias, el conflicto, el narcotráfico y la corrupción, sin caer en las categorías binarias de culpables e inocentes absolutos.

Otra inquietud propiciada por el libro y los sujetos de la investigación se refiere al papel de las mujeres, que están ausentes en los relatos y que suscitan preguntas como: ¿es posible identificar mujeres emprendedoras y empresarias cuya voz sea el centro de otras narrativas en el Pacífico? o ¿están estas actividades concentradas solo en los hombres por algunas circunstancias no establecidas en el libro?

Al margen de estos comentarios que sugieren apenas unas ideas para continuar con el diálogo abierto con los autores, el libro es, sin duda, un esfuerzo importante por mostrar la dimensión humana de los empresarios y emprendedores consultados. Es una manera de acercarse a distintas formas de resistencia y encaramiento de situaciones que demandan otros cálculos y estrategias, y que se suman a los procesos regionales de afrontar el conflicto y a la posibilidad de seguir subsistiendo a pesar de las incertidumbres y riesgos descritos en cada crónica. El libro nos invita a acompañar y comprender las experiencias y viajes narrados, y a sumergirse a través de los relatos de sus protagonistas en ese Pacífico tan bello pero aún tan agrietado. 


\section{Referencias}

Ricoeur, Paul. 2004. La memoria, la historia, el olvido. Buenos Aires: Fondo de Cultura Económica.

Varela, Rodrigo y Olga Lucía Bedoya Arturo. 2006. "Modelo conceptual de desarrollo empresarial basado en competencias”. Estudios Gerenciales 22 (100): 21-47. http://www.scielo. org.co/pdf/eg/v22n100/v22n100a01.pdf 